\title{
A ludicidade na EJA/Campo no contexto de uma escola da Comunidade Matinha dos Pretos, Feira de Santana - BA
}

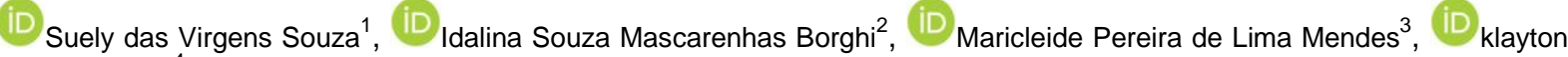
Santana Porto ${ }^{4}$

${ }^{1}$ Fazenda Alecrim Miúdo - Distrito de Matinha Feira de Santana. Feira de Santana - BA. Brasil. ${ }^{2,3,4}$ Universidade Federal do Recôncavo da Bahia - UFRB.

Autor para correspondência/Author for correspondence: suelydasvirgensfsa@hotmail.com.br

RESUMO. O presente trabalho é resultado de uma pesquisa que tem por objetivo compreender as concepções de ludicidade de uma professora de Ciências que atua na EJA/Campo e a importância atribuída a essa ferramenta pedagógica no ensino de Ciências, em uma escola quilombola do campo localizada no município de Feira de Santana/BA. O estudo foi balizado pelos princípios da abordagem qualitativa, do tipo estudo de caso, e para a coleta das informações foram utilizadas a entrevista semiestruturada, observação e análise documental. A pesquisa indica que a ludicidade inserida no contexto escolar e cotidiano do aluno precisa superar o caráter da brincadeira, constituindose como ferramenta fundamental para a promoção de propostas pedagógicas que despertem prazer, contribuindo para a aprendizagem do aluno de forma significativa, principalmente nesta modalidade de ensino, composta por atores sociais que foram excluídos da educação formal. Diante da análise dos resultados, constatamos certa contradição entre os discursos que circulam no ambiente escolar, o que foi observado em sala e o que consta no Projeto Político Pedagógico da escola, revelando um distanciamento entre o que se pensa sobre ludicidade e o que se faz na prática. Todavia, é fundamental reconhecer que os educadores não podem ser responsabilizados, quando da impossibilidade da mediação de práticas lúdicas, uma vez que não tiveram acesso à formação inicial e continuada condizente com tais práticas.

Palavras-chave: ludicidade, ciências da natureza, educação de jovens e adultos, educação do campo.

v. 6 e9700




\title{
Playfulness in Youth and Adult Education/Countryside in the context of a school from Matinha dos Pretos Community, Feira de Santana - BA
}

\begin{abstract}
The present work is the result of a research that aims to understand the concepts of playfulness of a science teacher who works at Youth and Adult Education/Countryside and the importance attributed to this pedagogical tool in science teaching, in a school in the field of the community of Quilombola, municipality of Feira de Santana-BA. The study was guided by the principles of the qualitative approach and the case study type, and semi-structured interviews, observation and document analysis were used to collect the information. The research indicates that the playfulness inserted in the student's school and daily context needs to overcome the character of play, constituting itself as a fundamental tool for the promotion of pedagogical proposals that arouse pleasure, contributing to the student's learning in a significant way, especially in this modality of education, composed of social actors who were excluded from formal education. In view of the analysis of the results, we found a certain contradiction between the speeches circulating in the school environment, what was observed in the classroom and what appears in the school's Political Pedagogical Project, revealing a gap between what is thought about playfulness and what is done in practice. However, it is essential to recognize that educators cannot be held responsible, when it is impossible to mediate playful practices, since they did not have access to initial or continuing training consistent with such practices.
\end{abstract}

Keywords: playfulness, natural sciences, youth and adult education, rural education. 


\section{Ludicidade en Educación de Jóvenes y Adultos/Campo en el contexto de una escuela de la Comunidad de Matinha dos Pretos, Feira de Santana - BA}

RESUMEN. El presente trabajo es el resultado de una investigación que tiene como objetivo comprender los conceptos de diversión de un profesor de ciencias que trabaja en Educación de Jóvenes y Adultos/Campo y la importancia atribuida a esta herramienta pedagógica en la enseñanza de las ciencias, en una escuela en el campo de la comunidad Quilombola, municipio de Feira de Santana-BA. El estudio se guió por los principios del enfoque cualitativo y el tipo de estudio de caso, y se utilizaron entrevistas semiestructuradas, observación y análisis de documentos para recopilar la información. La investigación indica que el juego insertado en la escuela y el contexto diario del alumno debe superar el carácter del juego, constituyéndose como una herramienta fundamental para la promoción de propuestas pedagógicas que despiertan placer, contribuyendo al aprendizaje del alumno de manera significativa, principalmente en esta modalidad de educación, compuesta por actores sociales que fueron excluidos de la educación formal. En vista del análisis de los resultados, encontramos una cierta contradicción entre los discursos que circulan en el entorno escolar, lo que se observó en el aula y lo que aparece en el Proyecto Político Pedagógico de la escuela, revelando una brecha entre lo que se piensa sobre el juego y lo que se hace en la práctica. Sin embargo, es fundamental reconocer que no se puede responsabilizar a los educadores, cuando es imposible mediar prácticas lúdicas, ya que no tuvieron acceso a una formación inicial o continua acorde con dichas prácticas.

Palabras clave: lúdico, ciencias de la naturaliza, educación de jóvenes y adultos, educación rural. 


\section{Introdução}

A Ludicidade é uma necessidade do ser humano em qualquer idade e, quando partimos para o campo educacional, não pode ser vista apenas como diversão. Trabalhar com o lúdico no processo de ensino e aprendizagem não significa apenas brincar, mas ampliar as oportunidades de aprendizado, possibilitando que os alunos adquiram os conhecimentos de maneira significativa e prazerosa.

De acordo com Apaz et al. (2012, p. 7), a palavra lúdico, etimologicamente, vem do latim lúdus e reporta-se a jogo, divertimento, associado ao brincar de forma livre individual, mas também referindo-se a comportamento social de jogar, utilizando regras, e aludindo à conduta social de recreação, apontando para uma maior abrangência das ações lúdicas. Assim, pode-se dizer que o lúdico é como se fosse uma parte inerente do ser humano, utilizado como recurso pedagógico em várias áreas de estudo, oportunizando a aprendizagem do indivíduo.

Nesse sentido, o lúdico é uma necessidade básica da personalidade, do corpo e da mente, pois faz parte das atividades essenciais da dinâmica humana. Com isso, as práticas lúdicas podem e devem ser utilizadas de diferentes em diversas faixas etárias, inclusive, na Educação de Jovens e Adultos (EJA).

A EJA é uma modalidade de ensino destinado aos jovens, adultos e idosos que não tiveram acesso à educação formal, ou acessaram a escola, mas não conseguiram permanecer, sendo excluídos do sistema educacional. Esta modalidade de ensino foi criada para proporcionar melhores condições de vida e trabalho para essas pessoas, que, ao acessarem a EJA, obtêm significativa melhora em seu conhecimento e autoestima, propiciando o seu desenvolvimento (Arroyo, 2017).

Arroyo (2017) afirma, ainda, que a EJA possui um público bastante diferenciado, heterogêneo e, em vista disto, se faz necessária a busca de estratégias e diferentes metodologias de ensino que venham a contribuir para o aprendizado dos alunos, bem como a permanência dos mesmos em sala de aula. Nesse sentido, defendemos práticas educacionais que tragam prazer ao serem realizadas e uma dessas práticas pode ser o desenvolvimento de atividades lúdicas, pois estas, como já sinalizado, proporcionam uma sensação de bem-estar e podem funcionar como instrumento de mediação da aprendizagem, aliada à descontração, pois, embora os estudantes da EJA não sejam mais crianças, um dia já foram e certamente 
aprenderam com esse recurso (Castilho \& Tonus, 2008).

As inquietações que desencadearam o ensejo de desenvolver essa pesquisa surgiram durante o período do estágio Supervisionado I, desenvolvido pela primeira autora na modalidade EJA, em uma escola quilombola do campo, localizada na zona rural do Município de Feira de Santana-BA. A Matinha dos Pretos foi reconhecida, recentemente, pela Fundação Palmares, como comunidade remanescente de Quilombo. No período do estágio foi percebido o desafio de mobilizar os estudantes para aprendizagens que fizessem sentido para a produção de suas vidas. E, percebendo a ausência de atividades lúdicas no processo de ensino e de aprendizagem, assumimos o compromisso de desenvolver pesquisas, em vista de buscar alternativas para trabalhar o lúdico na sala de aula.

A partir destas reflexões, esta pesquisa teve como objetivo compreender as concepções de ludicidade de uma professora de Ciências que atua na EJA/Campo e a importância atribuída a essa ferramenta pedagógica no ensino de Ciências, em uma escola quilombola do município de Feira de Santana/BA. Para isso, realizamos um período de observação do cotidiano da sala de aula, no estágio $\mathrm{V}$, que corresponde ao $8^{\circ}$ e $9^{\circ}$ ano do ensino fundamental, em uma turma de Ciências da Natureza, entrevistamos a professora de Ciências desta turma e fizemos uma análise do Projeto Político Pedagógico da escola.

Sendo assim, defendemos que a Educação do Campo, no contexto da EJA, precisa trabalhar a realidade, as experiências e as expectativas sociais, culturais e econômicas do grupo a que se destina. Essa educação precisa vir imbuída de consistente reflexão política e cidadã, do contrário, não obterá resultados concretos tão efetivos, já que a educação é uma ferramenta que visa preparar os sujeitos para o mundo do trabalho. E nesse sentido, acreditamos que a ludicidade, enquanto ferramenta pedagógica, poderá ter grande relevância no processo formativo dos estudantes da EJA.

Para tanto, organizamos este trabalho em cinco seções: introdução, referencial teórico, procedimentos metodológicos, a análise dos resultados da pesquisa e considerações finais. A primeira seção trata dos elementos introdutórios do trabalho, expondo a temática abordada e os objetivos do trabalho, justificando a relevância da pesquisa. Na segunda seção, dialogamos sobre o conceito de EJA, sua relação com a Educação do Campo e a ludicidade, refletindo sobre o ensino de Ciências na EJA/Campo e a prática lúdica 
nesse ambiente. Já na terceira seção, apresentamos os aspectos metodológicos da pesquisa, descrevendo os procedimentos e instrumentos para a coleta de informações. As últimas seções versam sobre a análise dos resultados da pesquisa, refletindo sobre as atividades lúdicas na realidade da EJA/Campo e as possibilidades vislumbradas. Por fim, apresentamos as considerações finais sobre o estudo desenvolvido, sugerindo uma experiência de EJA na perspectiva da Pedagogia da Alternância como possibilidade para o desenvolvimento de um trabalho lúdico e integrado com as vivências dos estudantes camponeses, como caminho para um ensino de Ciências que faça sentido para os estudantes que produzem suas vidas no campo.

\section{Diálogo sobre EJA, Educação do Campo, ludicidade e ensino de Ciências}

A EJA é uma modalidade educativa para Jovens e Adultos que, independente do motivo, não tiveram oportunidade de concluir o Ensino Fundamental ou Médio. De acordo com Galdino et al. (2012), a EJA é uma modalidade de ensino que busca amparar, equalizar e qualificar o ensino para jovens, adultos e idosos e que deve ser orientada pelos princípios de proporção, equidade e diferença. As autoras ainda argumentam que, como parte da Educação Básica, esta modalidade de ensino precisa primar pela cidadania dos jovens e adultos; e primando pela qualidade, constituído por educadores “... aptos a congregar, em seu trabalho, as inovações nas distintas áreas de conhecimento e de incorporar as mudanças sociais e as suas consequências na esfera escolar" (Galdino et al., 2012, p. 15).

Conforme Ajala (2011), os motivos que levam ao abandono escolar são: a necessidade de trabalhar; conflito na volta com a distorção idade/série que, muitas vezes, provoca nova evasão escolar; a distância da casa para a escola e a dificuldade de aprendizagem. Cabe citar ainda que muitos alunos reclamam de cansaço físico e manifestam vergonha de retornar ao ambiente escolar com idade mais avançada, não conseguindo conciliar o trabalho diário com as tarefas escolares.

Os motivos elencados reportam as consequências de um modelo de sociedade fundada nas bases escravocratas, que produziu grandes desigualdades sociais, demarcando o lugar de quem pode e de quem não pode ter acesso à escola. Esse acesso não se faz somente com a possibilidade de adentrar o espaço escolar, mas com condições estruturais para todas as pessoas ingressarem e permanecerem com dignidade, o que inclui condições materiais e imateriais, indispensáveis para 
garantir o senso de pertencimento do estudante ao espaço onde acontece a mediação de aprendizagens (Borghi \& Porto, 2019).

Quando partimos para a realidade dos alunos do campo, nos deparamos com jovens e adultos trabalhadores a quem foram negadas as condições para a efetivação do direito à educação. Esta negação é uma dívida histórica da sociedade brasileira para com os sujeitos que fazem parte do segmento EJA/campo. Inspiradas em Freire (1967), podemos afirmar que a EJA e a Educação do Campo são tratadas como territórios marcados por lutas e conquistas históricas no campo da educação e, por se tratar de experiências educacionais

historicamente negligenciadas pelas políticas públicas educacionais, constituem-se também enquanto campo de importantes lutas pelo processo de democratização da sociedade brasileira.

Para autores como Caldart e Molina (2011) e Arroyo (2017), a Educação do Campo surge da luta dos movimentos sociais do campo pelo direito à educação, associada, principalmente, à luta pela terra que gera trabalho e cidadania. Para estes autores, esta não pode ser qualquer educação, mas uma educação que se contrapõe à subordinação e às relações de poder e de dominação da população campesina à cultura urbanocêntrica.

\begin{abstract}
A educação do campo é aquela que trabalha os interesses, a política, a cultura e a economia dos diversos grupos de trabalhadores e trabalhadoras do campo, nas suas diversas formas de trabalho e de organização, na sua dimensão de permanente processo, produzindo valores, conhecimentos e tecnologias na perspectiva do desenvolvimento social e econômico igualitário desta população (Araújo \& Porto, 2019, p. $4)$.
\end{abstract}

As ideias desses autores dialogam com as proposições de Paulo Freire (1967), ao afirmar que o papel primordial da educação na construção da formação dos sujeitos é o de sua libertação, levando-os a compreender o mundo no qual estão inseridos, as possibilidades de sua transformação e, em consequência, a transformação do mundo.

Coadunando com as ideias de Freire (1967), defendemos que a transformação não se dá por um modelo de educação bancária, na qual o sujeito que aprende é um sujeito passivo, um ser que não reflete, mas por meio de uma educação que liberta e que vai além dos saberes puramente técnicos e nos dá a condição de refletir sobre quem somos, por que somos e para que somos formados.

Dessa maneira, evidencia-se que as propostas pedagógicas para a EJA/Campo precisam atender às necessidades 
específicas dos sujeitos da EJA, considerando também às particularidades de quem vive e trabalha no campo. É importante ressaltar, ainda, que nem sempre o currículo e os conteúdos estão adaptados para os alunos do campo, o que dificulta a aprendizagem dos conhecimentos socializados na escola e o diálogo com as demandas da vida no campo fica desencontrado, o que não permite ao estudante da EJA/Campo encontrar o sentido dos conteúdos socializados para a produção da vida no campo.

Com relação aos conceitos de EJA e Educação do Campo, Arroyo (2017) defende que as conquistas da Educação de Jovens e Adultos permanecem integradas com os movimentos sociais dos trabalhadores do campo, que passaram a exigir maior engajamento político do direito à Educação dos estudantes da EJA, valorizando o trabalho do campo e defendendo a cidadania. A partir da luta e resistência desses trabalhadores, novas concepções de ensino foram emergindo e, por meio de organização de fóruns de EJA, construção de políticas públicas especificas para atender demandas especificas dos estados, foram se consolidando experiências de educação mais digna e humana, a fim de combater a exclusão social que, ao longo da história, vitimou os sujeitos da EJA.

Para Arroyo (2017), isso trouxe a representação e conscientização do direito a terra, trabalho, justiça, igualdade, conhecimento, cultura, saúde e educação. E o reconhecimento dos sujeitos jovens, adultos e idosos do campo, enquanto sujeitos de direitos, se dá através da realização de lutas e ações de mulheres e homens do campo. Sendo assim Alencar, Santos e Carvalho, (2016, p. 63) contribuem com essa discussão, afirmando que:

\begin{abstract}
A Educação de Jovens e Adultos EJA e Educação do campo, como campos de conhecimento em diálogo, produzem um fazer pedagógico potencializador de experiências diversas e algumas inovadoras; porém suas bases de construção são, muitas delas, de difíceis conquistas porque exigem a desconstrução de um modelo de mundo solidificado nas bases do capital e do mercado. Mas, não impossíveis. Cada aluno/a que frequenta as classes da EJA destinada à população do campo são exemplos de renovação e da construção de uma etapa diferente daquela que muitos de nós conhecemos (Alencar, Santos \& Carvalho, 2016, p. 63).
\end{abstract}

Nessa perspectiva, Arroyo (2017) afirma que a EJA deve atender às necessidades dos indivíduos que, muitas vezes, vão do trabalho direto para a sala de aula, moram em bairros ou comunidades distantes da unidade de ensino, e são de 
diversas identidades coletivas, provenientes do território social e espacial que ocupam. $\mathrm{O}$ autor ressalta que $\mathrm{o}$ currículo da EJA deve ser repensado para que seja possível aprofundar conhecimentos e atender à dinâmica que compõe a produção e exploração do trabalho, visto que os alunos da Educação de Jovens e Adultos são trabalhadores que buscam sobreviver na sociedade.

Nesse contexto, cabe-nos ressaltar que os componentes território, natureza (ambiente), a soberania popular (cidadania), a resistência crítica e democrática e a renovação das lutas e dos ambientes institucionais, bem como as questões políticas, socioeconômicas, culturais, científicas e tecnológicas são subsídios transversos da Educação do Campo (Ferreira \& Porto, 2020), em especial da EJA/Campo. Uma vez que a EJA e a Educação do Campo devem resguardar uma concepção educativa que se materialize na escola, de modo que esta escola seja do campo e não apenas para o campo. Vivenciar uma proposta educativa do campo e no campo necessita da identificação e da edificação de uma identidade escolar banhada pela territorialidade e toda sua historicidade, cultura e formas de viver (Santos \& Porto, 2020).
Percebe-se que o diálogo entre as práticas educativas escolares e as práticas educativas das comunidades é um dos principais desafios que a Educação do Campo, em especial a EJA/Campo, tem enfrentado. Isso significa que o fortalecimento de uma educação do campo e no campo não pode prescindir de um currículo conectado com as demandas dos estudantes camponeses.

A Educação de Jovens e Adultos destinada aos sujeitos do Campo precisa oferecer subsídios para garantir as aprendizagens dos conhecimentos disponibilizados pela escola e, ao mesmo tempo, melhorar suas condições de vida. Pois o acesso à educação é parte dos direitos que foram negados aos sujeitos pauperizados e, portanto, os conhecimentos apreendidos na escola devem contribuir para melhorar as condições de produção da vida de Jovens e Adultos no campo.

Alinhar uma educação pública para os jovens e adultos do campo com a construção de um projeto de mundo nas bases da igualdade, solidariedade e justiça é, sem dúvida, o desafio que educadores, educandos, movimentos sociais e gestores públicos devem enfrentar (Santos, Jesus \& Porto, 2020). Desse modo, defendemos que a prática pedagógica, quando contextualizada, tem o poder de influenciar 
o rendimento do aluno e melhorar o envolvimento das pessoas e, por consequência, produzir mais conhecimento (Lopes, Mendes \& Faria, 2006).

As atividades lúdicas no ambiente educativo possibilitam a construção de ações pedagógicas que buscam a autoexpressão e socialização dos indivíduos, uma vez que estes devem ser estimulados a superarem seus próprios obstáculos de aprendizagem. De acordo com Vygotsky (1989), o caráter lúdico influencia o crescimento do indivíduo, melhorando seu modo de agir, aumentando sua curiosidade acerca dos ambientes nos quais permanece inserido, desenvolve seu potencial de iniciativa e autoconfiança, além de contribuir com o desenvolvimento da linguagem, pensamento e emoções.

Ressalta-se que a rotina juntamente com a monotonia escolar reduz o rendimento do aluno, bem como a motivação pedagógica; enquanto que o dinamismo e ludicidade das atividades no repertório escolar repercutem na forma de explorar o entendimento do aluno, promovem novas práticas, descortinando um mundo novo do saber. Isso contribui para a construção de uma cultura e conhecimento capazes de mudar o modo como estudantes e professores lidam com os processos de construção do conhecimento.
A EJA precisa ser um ambiente de estudo prazeroso, motivador, que gere a satisfação pessoal do aluno. Diante disso, é preciso pensar em formas de mudanças que possam contribuir para uma aprendizagem significativa, incluindo esses atores sociais, que foram historicamente excluídos dos processos educativos.

O lúdico gera uma movimentação, uma ação aliada às estratégias de ensino. As atividades lúdicas precisam extrapolar a dimensão da recreação e proporcionar ao educando uma apropriação de conhecimentos. Assim sendo, por meio dos jogos e brincadeiras, pode-se produzir um ambiente provocador de aprendizagens de forma leve, significativa e, de maneira tangível, abranger os aspectos éticos, estéticos, artísticos, técnicos etc. Diante do exposto, compartilhamos com Leite e Belo (2016, p. 14) a compreensão de que:

A ludicidade tem sido uma sugestão inovadora para a EJA, pois ainda é percebido que a metodologia aplicada a esse público ainda se apresenta de forma tradicional, sem levar em consideração o conhecimento prévio. Sendo assim: a ludicidade entra nesse contexto para fazer com que esses indivíduos sejam sujeitos de direitos, participantes e protagonistas de sua história fazendo-os compreender a realidade em que vivem, tendo conhecimento formal como armadura para protegê-los de uma possível alienação política. Para isso o lúdico proporciona a esses indivíduos uma releitura de mundo, de forma descontraída e prazerosa, resgatando valores e alegrias que estavam 
adormecidas pelo tempo e pelo trabalho enfadonho do cotidiano desses jovens e adultos (Leite \& Belo, 2016, p. 14).

Com base nos autores supracitados, a ludicidade é considerada um suporte pedagógico para uma melhor aprendizagem do aluno, sendo essa ferramenta uma maneira de ensinar, com recurso diferenciado, que possibilite ao aluno uma maior compreensão do conteúdo abordado.

A ludicidade pode facilitar a prática da Educação do Campo, permitindo que o aluno desenvolva suas próprias capacidades e identifique novos potenciais para a obtenção do conhecimento e formação educativa. Isso é fundamental para o desenvolvimento pessoal, social e profissional do educando, que, ao se manter em contato com ações lúdicas, consegue melhorar sua percepção sobre os conteúdos antes considerados como difíceis ou complicados. Dessa maneira, o lúdico melhora os aspectos intelectuais, cognitivos e afetivos, pois visa à apropriação de estratégias construídas com elementos da vivência e da cultura dos estudantes.

Como já sinalizado, a ludicidade é um suporte pedagógico e como tal pode ser utilizado no contexto do ensino de Ciências. Ensinar Ciências não significa apenas transmitir informações e apresentar conteúdos prontos de um livro didático. Para além disso, o ensino de Ciências, e aqui nos reportamos ao ensino de Ciências para alunos do campo, deve contribuir para a compreensão da realidade, pois aprender Ciência é aprender uma forma de obter uma visão crítica do mundo e compreender como os conteúdos de Ciências da Natureza podem contribuir para a produção da vida sustentável no campo.

Nesse sentido, Santos e Porto (2020) ressaltam que o estudo das Ciências, na realidade escolar do campo, deve favorecer o aprendizado sobre os sujeitos que vivem nele, suas formas de sobrevivência e a evolução histórica de sua realidade social, econômica e cultural ao longo do tempo; dando atenção também à macro realidade, ou seja, aos aspectos do mundo material como um todo, abrangendo o meio ambiente, com seus recursos naturais, e consequentes transformações ocasionadas pela ação do homem sobre a natureza; o conhecimento e a valorização da fauna, da flora e da vida, em suas mais variadas espécies e formas; a busca pelo conhecimento quanto ao Universo, o Sistema Solar e seus movimentos, dentre outros.

Nessa perspectiva de ensino, se faz necessário desenvolver atividades lúdicas articuladas à atividade científica e ao contexto do educando, uma vez que não 
tem sentido desenvolver atividades baseadas em modelos fundamentados somente na explicação do professor e na realização de resolução de exercícios. Utilizar a ludicidade como prática pedagógica é uma das diversas maneiras de mobilizar a aprendizagem de conteúdos e tornar o processo de ensino e aprendizagem mais dinâmico. Porém, apesar das práticas lúdicas facilitarem a aprendizagem dos conteúdos, o objetivo das mesmas, segundo Almeida (2016), não é apenas levar o estudante a aprender brincando, mas sim provocar à reflexão, ao raciocínio e à construção do conhecimento de maneira que o mesmo possa refletir e vivenciar de forma prática o conteúdo.

Moreira e Pinto (2003) ressaltam que para que os alunos possam se interessar e aumentar seu potencial de percepção para as leis das Ciências é imprescindível que possam relacionar o método ou as fórmulas com os seus conhecimentos prévios. Para isso, os autores revelam que existe a necessidade de mudar as propostas pedagógicas no ensino da Ciência, já que o objetivo envolve a aprendizagem significativa e não a aprendizagem mecânica.

Considerando que antes de iniciar a vida escolar os estudantes da EJA convivem continuamente com fenômenos e transformações naturais e com aparatos tecnológicos em seu cotidiano, o ensino das Ciências da Natureza na EJA/Campo deverá partir das concepções prévias desses estudantes sobre o mundo natural e social no qual estão inseridos e sobre os fenômenos e transformações que os permeiam. A partir dessa primeira leitura de mundo, os conhecimentos científicos poderão ser expostos às educandas e aos educandos, de modo a propiciar o diálogo do conhecimento científico acadêmico com o conhecimento popular e proporcionar momentos de aprendizagem, nos quais os alunos aprendam novos conhecimentos e possam vivenciá-los, experimentá-los na realidade de sua comunidade e no seu cotidiano (Santos \& Porto, 2020).

Essa prática possui grande relevância, pois contribui para que os estudantes da EJA/Campo possam observar a realidade imediata de suas comunidades, a partir de uma compreensão mais crítica acerca dos conhecimentos científicos que nelas se fazem presentes. Além disso, esse tipo de ação visa ao resultado de um processo de planejamento ligado à escolha de conteúdos, procedimentos, atividades, recursos físicos, humanos e intelectuais, estratégias, instrumentos para avaliação, metodologia, enfim, tudo que propicia maior entendimento dos assuntos. Cabe ressaltar que o ensino de Ciências na Educação do 
Campo deve buscar superar as dificuldades dos estudantes em adquirir o conhecimento, visando desenvolver novas potencialidades e fortalecer as capacidades já existentes. Sabe-se que as questões ambientais, ligadas à rotina de trabalho dos alunos na EJA, podem se transformar em conteúdos pedagógicos, ampliando as formas de aprendizagem e, consequentemente, contribuindo para que os estudantes permaneçam interessados em frequentar o ambiente escolar.

\section{Percurso metodológico}

Para o desenvolvimento do trabalho foi utilizada a abordagem qualitativa, recorrendo à entrevista semiestruturada, observação e análise do Projeto Político Pedagógico (PPP) da escola, como instrumentos para viabilizar o acesso às informações necessárias ao alcance dos objetivos deste estudo. Tratou-se de uma pesquisa qualitativa, por esta abordagem abranger o conhecimento que é um "processo dinâmico e inacabado, e servir como referencial ... das relações sociais, como forma de busca de conhecimentos próprios das ciências exatas e experimentais" (Gerhardt \& Silveira, 2009, p. 17).

Esta pesquisa procurou compreender o universo particular da EJA/Campo no que se refere ao uso e importância da ludicidade como uma ferramenta pedagógica nesta modalidade educativa. Com o intuito de responder ao objetivo desta investigação, participou da pesquisa uma docente que ministra aula no componente curricular na EJA/Campo, em uma escola quilombola, da Rede Municipal de Feira de Santana-BA. Durante a pesquisa foi estabelecida uma relação de diálogo com a professora que participou do estudo, mantendo um debate harmonioso entre os investigadores e a investigada, por meio de entrevistas semiestruturadas. Cabe ressaltar que o diálogo harmônico foi possível em razão da flexibilidade proporcionada pela entrevista semiestruturada, que permite ao pesquisador seguir determinadas questões previamente definidas, se assemelhando a uma conversa informal (Lakatos \& Marconi, 2010).

Para viabilizar o diálogo, foi necessária maior flexibilidade na conversa, especialmente quando surgiam elementos pertinentes no momento da entrevista que não estavam previstos nas expectativas da pesquisa. Por isso a importância de escolher esse caminho metodológico, a fim de acessar melhor o conhecimento da docente entrevistada.

O primeiro contato para a realização da pesquisa foi com a vice-diretora, quando explicamos o tipo de estudo a ser 
realizado e apresentada a temática da pesquisa, juntamente com a carta de apresentação, o termo de anuência da escola e o termo de consentimento livre e esclarecido. Após a apresentação dos documentos, foi obtida a resposta favorável ao desenvolvimento da atividade proposta e assinado o termo de anuência pela diretora, para então procedermos com a coleta das informações.

A entrevista foi realizada com uma professora de Ciências da Natureza, não havendo critério de escolha da professora, pois a escola só possuía uma única professora deste componente curricular na EJA. Assim, para fins de preservação da identidade da professora, optamos por não identificar o nome da escola. Esta profissional possui formação em Ciências Biológicas e trabalha na escola nos três turnos. Além disso, atua como docente há 19 anos e na EJA há 9 anos. Após conversa com a professora, entregamos duas cópias de igual teor do termo de consentimento livre e esclarecido, que após lidas, foram assinadas pela professora e pelos pesquisadores, seguindo todas as orientações e aspectos éticos da resolução $n^{\circ} 466$ de 2012, do Conselho Nacional de Saúde. Somente de posse desse documento devidamente assinado, iniciamos a entrevista, tomando como base oito questões norteadoras, com enfoque na concepção e importância da ludicidade na EJA/Campo. Posteriormente, foi feita a observação sistemática das aulas ministradas pela docente, a fim de entender em que medida as atividades lúdicas eram desenvolvidas em sala de aula.

Em se tratando de entrevista $\mathrm{e}$ observações, Ludke e André (1986) afirmam que estes instrumentos ocupam:

... um lugar privilegiado nas novas abordagens de pesquisa educacional. Usada como o principal método de investigação ou associada a outras técnicas de coleta, a observação possibilita um contato pessoal e estreito do pesquisador com o fenômeno pesquisado, o que apresenta uma série de vantagens. Em primeiro lugar, a experiência direta é sem dúvida o melhor teste de verificação da ocorrência de um determinado fenômeno. "Ver para crer", diz o ditado popular (Ludke \& André, 1986, p. 86).

As observações ocorreram no estágio $\mathrm{V}$, que corresponde ao $8^{\circ}$ e $9^{\circ}$ ano do ensino fundamental e, como discutem Ludke e André (1986), a observação é o momento de conhecer de perto a prática de sala de aula, mesmo já conhecendo a realidade da escola, essa foi uma experiência singular, pela possibilidade de observar a prática com foco na ludicidade, compreendendo os desafios, possibilidades que tantas vezes são desperdiçados por falta de maior aproximação com a realidade dos estudantes e com as discussões específicas da EJA/Campo. 
Foi durante o período de observação que percebemos o quanto o diálogo entre a realidade dos estudantes e a ludicidade pode contribuir para mobilizar as aprendizagens dos conteúdos, estreitando as relações entre trabalho e educação e evitando práticas infantilizadoras.

\section{O lúdico no Projeto Político Pedagógico da escola}

A análise documental do Projeto Político Pedagógico (PPP) da escola se tornou necessária, sendo este tipo de análise uma técnica valiosa para complementar as informações obtidas na entrevista com a professora, desvendando aspectos que podem não ser evidenciados durante a entrevista.

Para Vasconcelos (2000), o PPP constitui a sistematização das diretrizes de trabalho da escola e deve fazer parte do processo de construção participativo desta, que vai definir as ações educativas a serem desenvolvidas neste ambiente. É um plano de organização do trabalho que a escola se propõe a realizar. O PPP pesquisado foi elaborado pela comunidade escolar, definido pela Secretaria de Educação do Município de Feira de Santana-BA (SEDUC), que solicitou a Unidade de Ensino que realizasse as adequações necessárias para a implementação da modalidade Educação Escolar Quilombola, porque a escola está localizada numa comunidade quilombola.

Diante da solicitação, essa proposta pedagógica foi construída coletivamente, levando em consideração tanto a cultura local, como a ancestralidade, as questões étnicas, sociais e políticas do lugar. De acordo com o PPP, a escola busca trabalhar sua proposta pedagógica para a formação de cidadãos com senso crítico e reflexivo, possibilitando a interpretação da vida e do mundo.

Conforme o documento da escola pesquisada, a instituição busca ainda formar alunos como sujeitos livres e conscientes dos seus direitos e deveres, garantindo assim um exercício pleno da sua cidadania em sociedade, contribuindo significativamente para a melhoria de suas vidas. De acordo com o PPP, a escola deve difundir esses aspectos como processo de identidade dos estudantes quilombolas.

O PPP propõe também que a escola estimule o aluno a adquirir hábitos e habilidades favoráveis ao trabalho em grupo. Ao pensar no desenvolvimento dos alunos, a escola busca ampliar em sua prática pedagógica estratégias de ensino diversificadas, com a criação de projetos que envolvam todo âmbito escolar: essas atividades diferenciadas têm a participação efetiva de alunos do matutino e vespertino 
e, no noturno com a modalidade da EJA, ainda são apresentadas de forma tímida.

As estratégias diversificadas utilizadas são: projetos, gincana, feiras, oficinas, apresentações culturais, atividades relacionadas às datas comemorativas, como a semana da consciência negra, dentre outras, que são atividades lúdicas. Todavia, torna-se necessário trabalhar estas atividades articuladas aos conteúdos curriculares, para que não se restrinjam apenas a diversão, mas passem a fazer parte da prática pedagógica da escola, se configurando como atividades significativas para o aprendizado coletivo dos alunos da EJA/Campo.

\section{Diálogo entre ludicidade e a experiência da professora de Ciências da Escola da Comunidade Matinha dos Pretos}

Nesta seção, apresentamos os resultados da entrevista com a professora identificada com o nome fictício de Flávia, atualmente professora da EJA/Campo. Nesta reflexão, buscamos dialogar sobre a importância da ludicidade na EJA/Campo, visando uma investigação que proporcione o entendimento da concepção da professora acerca desta ferramenta nas aulas ministradas para jovens e adultos.

Quando indagada sobre o tema proposto, as respostas foram bem objetivas. Em relação a sua compreensão de ludicidade, a professora afirma que "são jogos e brincadeiras utilizadas em atividades, com o objetivo de desenvolver nas pessoas envolvidas habilidades/ou competências, aprendizados de forma divertida" (Flávia, 2018).

De acordo com a resposta da docente, verifica-se que ela possui conhecimentos acerca dos objetivos da ludicidade, no entanto essa estratégia de ensino não deve ser vista apenas como jogos e brincadeiras. De acordo com Luckesi (2014, p. 18), a ludicidade é definida como: “... um estado interno, que pode advir das mais simples as mais complexas atividades e experiências humanas. Não necessariamente a ludicidade provém do entretenimento ou das brincadeiras. Pode advir de qualquer outra atividade que faça os olhos brilharem".

A ludicidade não é igual para todos. Experiências que podem gerar satisfação para um, podem não apresentar o mesmo resultado para outro. Dessa forma, há que se considerar que as práticas pedagógicas na EJA/Campo precisam ser desempenhadas em razão de um fazer criativo e lúdico, permitindo o entendimento da realidade dos estudantes, para que eles alcancem maior sentido na aprendizagem. 
Quando abordada sobre o uso de atividades lúdicas em suas aulas, com estudantes da EJA, a docente afirmou que adota estas ações em algumas ocasiões, pois:

... devido à dificuldade de materiais didáticos adequados e também à dificuldade de entrosamento dos alunos, que não querem participar de algo novo, preferem a aula expositiva. Os alunos também se mostram desinteressados e com comportamento inadequado, sendo um grande desafio introduzir atividades lúdicas em sala (Flávia, 2018).

A docente diz ainda que os alunos que preferem aulas expositivas são os alunos mais velhos, acostumados ao tradicionalismo do quadro, livro e caderno. Esses alunos são citados como tímidos, não se sentindo à vontade para participar de atividades diferenciadas. A professora salientou que quando utiliza estratégias lúdicas em sala faz uso de experimentos, oficinas, cartazes, mural, e apresentações culturais.

$$
\text { Para driblar esses desafios, }
$$
sinalizados pela docente, Luckesi (2014) propõe que a ludicidade na maturidade deve ser praticada a partir de ações como pintura, música, escrita, e outras atividades que aliem o entretenimento e lazer ao aprendizado significativo.

É preciso refletir sobre a melhor forma de trabalhar a ludicidade na realidade da EJA/Campo, em uma comunidade quilombola, a fim de valorizar o trabalho e as experiências construídas pelos alunos em sua vida cotidiana, uma vez que estas experiências podem ser transformadas em conteúdos pedagógicos.

Nesta busca, a professora Flávia trata da reação dos alunos perante os trabalhos efetuados com ludicidade, a professora afirma que "alguns têm dificuldade de entrosamento e não querem participar de algo novo, preferindo aula expositiva". Reafirmando o que tinha dito anteriormente, a professora se posiciona sobre o papel da ludicidade na aprendizagem dos estudantes da EJA, afirmando que

Atividades lúdicas facilitam a aprendizagem, no entanto essa não deve ser a única, a aula expositiva também se mostra muito importante. A ludicidade facilita a aprendizagem, pois 0 educando consegue compreender na prática os conteúdos trabalhados teoricamente durante as aulas expositivas. A ludicidade é um complemento para o aprendizado do aluno. As duas estratégias de ensino devem caminhar juntas para um melhor resultado (Flávia, 2018).

Embora a professora trabalhe a ludicidade de vez em quando, a mesma a considera como importante ferramenta no processo de ensino e de aprendizagem, considerando uma forma de mobilizar a aprendizagem de maneira divertida, tornando as aulas teóricas enriquecedoras. 
Na EJA/Campo, o lúdico precisa ser trabalhado a partir das experiências de vida dos estudantes, ampliando as possibilidades de aprendizado, pois constitui-se um instrumento metodológico que pode oferecer maior sentido ao conhecimento, deixando as aulas mais prazerosas e possibilitando o diálogo com a vida cotidiana do estudante do campo. Para Oliveira (2016, p. 02) é este sentido que a EJA trabalhada com ludicidade “... pode tornar-se para os educandos um espaço privilegiado de formação com metodologias divertidas e dinamizadas, desfrutando de momentos prazerosos ao mesmo tempo construindo um conhecimento escolar agradável”.

Considerando que a escola está inserida em uma comunidade quilombola, é preciso considerar que as festas e as manifestações culturais são características de sua existência, enquanto comunidade quilombola com muitos saberes ancestrais marcados pelos afetos. Nos períodos festivos, os laços e vínculos da comunidade são fortalecidos pela fé, sendo possível retornar às suas origens e contribuir com a continuação de crenças e rituais praticados por seus antepassados. Nesse sentido, a professora poderia aproveitar essa riqueza de simbolismo cultural e religioso para implementar as práticas educativas lúdicas na escola, de modo a permitir que os costumes e crenças dos povos quilombolas sejam transformados em conteúdos pedagógicos.

Talvez uma das possibilidades seria articular a Ludicidade com a Pedagogia da Alternância, a qual entendemos com Silva (2003) como conjunto de estratégias de escolarização para possibilitar aos jovens e 'Adultos' conciliar a formação escolar com atividades desenvolvidas na unidade produtiva familiar, vinculando família e cultura camponesa.

Na visão de Silva (2009), a organização das práticas pedagógicas e mediação dos conteúdos nas escolas do campo requer que se considerem as condições sociais, políticas e culturais da comunidade onde os estudantes estão inseridos. Com isso, será possível aliar os conteúdos teóricos com os conhecimentos obtidos e construídos fora da escola, fomentando a ampliação e transformação dos saberes aprendidos de maneira mais dinâmica, permitindo que os alunos da EJA permaneçam ativos em seu próprio desenvolvimento. Nesses termos, a Pedagogia da Alternância é um caminho promissor para alinhar os conteúdos teóricos com os saberes produzidos fora do espaço escolar e, portanto, pode ser considerada uma proposta viável para balizar as práticas pedagógicas na EJA/Campo. 
A prática pedagógica na educação do campo baseada na Pedagogia da Alternância é voltada para a formação do povo do campo, que consiste na organização escolar diferenciada, onde os estudantes articulam os conteúdos com os saberes adquiridos na dinâmica do trabalho (Porto, Duboc \& Ribeiro, 2021). Entendendo o trabalho como um princípio educativo que envolve condições sociais e culturais. Uma ludicidade que se desenvolve no contexto de produção de vida dos sujeitos não será vista pelos estudantes com estranhamento. Essa é uma experiência inspiradora e pode ser capaz de fomentar um fazer educativo criativo e lúdico, oferecendo maior sentido à aprendizagem dos estudantes da EJA/Campo, de modo que os conteúdos ensinados façam parte da realidade dos estudantes.

Com relação aos desafios e possibilidades do trabalho com ludicidade na EJA/Campo, a professora Flávia ressalta que:

Um dos desafios é encaixar atividade e conteúdo de forma lúdica numa carga horária tão reduzida e também fica difícil a inclusão das atividades didáticas pedagógicas no planejamento anual das disciplinas, levando em consideração as séries dos alunos e a realidade local (Flávia, 2018).
Foi perguntado também sobre o papel das atividades lúdicas na relação aluno/aluno e professor/aluno, sendo evidenciado que:

É uma possibilidade de entrosamento, socialização e participação. Durante a realização de atividades lúdicas ocorrem momentos de interação entre os alunos. Essa interação ajudara na compreensão dos conteúdos propostos, estimulados por situações que envolvem descontração e estímulo a aprendizagem (Flávia, 2018).

Outra questão buscou identificar se a escola costuma proporcionar experiências lúdicas aos alunos. Segundo Flávia, a escola oferta essas ações, apresentando maior participação dos alunos ingressantes no período diurno. Verificou-se ainda que dentre as atividades lúdicas mais desenvolvidas na escola estão "alguns projetos ao longo do ano, desenvolvidos em todas as turmas, envolvendo todas as disciplinas, com temas como sustentabilidade na escola, reciclagem de óleo usado para transformar em sabão, semana da consciência negra, horta na escola etc." (Flávia, 2018).

Por fim, dialogamos sobre como evitar o "fracasso" e a evasão escolar, uma das grandes preocupações da EJA/Campo. Foi perguntado à professora quais os fatores que provocam a evasão e quais metodologias podem contribuir para a permanência do estudante da EJA na 
escola. Flávia se posicionou afirmando que:

Sabemos que a EJA é uma realidade bem diferente do diurno; na maioria são alunos, que por diversos motivos se afastaram dos estudos e retornaram mais tarde para concluilos. Os mais jovens costumam evadir por questões comportamentais (entorpecentes, má conduta), os mais velhos por trabalho, família. Há também as dificuldades de locomoção e transporte, período de chuvas, onde são realizadas as plantações e esses alunos pelo cansaço do trabalho árduo na roça, acabam faltando bastante as aulas. Há também na escola os alunos da EJA, que trabalham no comércio, indústrias e como diaristas. Diante desses motivos o aluno se afasta, naturalmente, impossibilitando a continuidade dos estudos. Nesses casos, a escola não tem muito o que fazer para mantê-los em sala de aula (Flávia, 2018).

Conforme as diretrizes operacionais da Educação do Campo (Brasil, 2002), a aceitação e inserção dos alunos na EJA podem ser promovidas mediante a facilitação da participação deles nas atividades pedagógicas. Segundo as diretrizes educacionais da Educação do Campo, os povos do campo têm direito à alteração do calendário letivo para atender suas demandas de trabalho. Ou seja, suspensão das aulas nos períodos em que as atividades agrícolas são mais intensas.

Nesse contexto, mais uma vez nos reportamos à importância da Pedagogia da Alternância que, conforme relatam Silva e
Miranda (2012), facilita a inclusão dos estudantes na EJA, de modo a flexibilizar os horários e os conteúdos que fazem parte do currículo escolar, valorizando-os enquanto sujeitos ativos no processo de aprendizado e de trabalho. Assim, a Pedagogia da Alternância e a ludicidade podem contribuir para uma aprendizagem que integre trabalho e escola, melhore a permanência dos alunos do campo na sala de aula, evitando o distanciamento da escola, pois muitos deles trabalham durante o dia e, no período noturno, estão cansados, o que dificulta a dedicação aos estudos ou o deslocamento até a unidade de ensino.

As vivências durante 0 tempo Comunidade criarão relações afetivas significativas entre os alunos do campo, pois trazem à tona conhecimentos em comum e diferentes, que podem ser compartilhados, onde o cotidiano das famílias quilombolas pode ser discutido, valorizando as lutas, aspirações, crenças e costumes.

Com os dados obtidos durante a entrevista com a professora, percebemos que ela compreende o que é ludicidade e como essa ferramenta pode contribuir de forma significativa para o processo de ensino e de aprendizagem de alunos da EJA. No entanto, há uma contradição nas respostas da educadora, pois se levarmos 
em consideração o discurso da mesma e o que foi observado na prática e na resposta anterior da professora, quando afirma que usa a ludicidade apenas de vez em quando, há um grande distanciamento entre o que pensa sobre ludicidade e o que é feito na prática. Esse entendimento se justifica com a observação das aulas, visto que a professora priorizava a explanação dos assuntos a partir da escrita de algumas observações no quadro e seguindo fielmente o livro didático.

A pesquisa revelou que há na escola trabalhos que envolvem atividades lúdicas. Essas estratégias são adotadas em algumas ocasiões, como relatado pela professora e descrito no PPP da instituição. Essas atividades são realizadas esporadicamente em datas comemorativas e em eventos realizados pela escola, sem levar em consideração que o lúdico precisa ser um trabalho contínuo durante a mediação dos conteúdos programáticos, sendo valorizado o conhecimento prévio do aluno e uma relação intensa com as práticas socioculturais presentes no cotidiano dos estudantes da EJA/Campo e não apenas trabalhos pontuais em algumas circunstâncias. Todavia, precisamos reconhecer o esforço da professora, haja vista que dentro das condições de possibilidades que tem, ela se esforça para fazer o que considera melhor para o grupo.
O que não podemos é fechar os olhos para a negligência do poder público, sobretudo, no que se refere à formação continuada na especificidade da EJA/Campo.

\section{Considerações finais}

Considerando o objetivo geral deste estudo, compreender as concepções de ludicidade de uma professora de Ciências que atua na EJA/Campo e a importância atribuída a essa ferramenta pedagógica no ensino de Ciências, na comunidade de Matinha dos Pretos, município de Feira de Santana/BA, percebe-se que a concepção da professora participante da pesquisa sobre ludicidade aproxima-se de uma ludicidade que utiliza os jogos e brincadeiras como forma de abordar as questões do contexto do aluno.

Durante a pesquisa, observamos que a professora era muito dedicada, mas não tinha condições objetivas para desenvolver uma prática lúdica, em conexão com as dinâmicas de vida dos estudantes, o que significa trabalhar a ludicidade por meio dos fenômenos sociais e culturais que compõem a vida do estudante campesino. Nossa luta por educação de qualidade para os sujeitos dessa modalidade educativa precisa incluir práticas pedagógicas vinculadas à realidade dos estudantes em processo de aprendizagem, a fim de assegurar maiores oportunidades de 
desenvolvimento. Os professores também precisam se engajar em formações continuadas, voltadas para as especificidades da EJA e da Educação do Campo, para aprimorar conhecimentos e desenvolver novas estratégias de ensino que respondam efetivamente às demandas dos sujeitos da EJA. Todavia, a responsabilidade pela busca do aperfeiçoamento não pode ser delegada somente ao(à) professor(a). As secretarias de educação precisam planejar formação continuada, especificas para os professores que trabalham na EJA/Campo, sem penalizar seus dias de descanso.

Sobre a concepção e importância da ludicidade na Educação de Jovens e Adultos, conforme exposto no referencial teórico e na entrevista da professora, a ludicidade inserida no contexto escolar e cotidiano do aluno supera o caráter de brincadeira, e precisa ser utilizada como uma ferramenta para a promoção de propostas pedagógicas que despertem prazer, contribuindo para a aprendizagem do aluno de forma qualitativa, principalmente nesta modalidade de ensino, composta por atores sociais que foram excluídos dos processos educacionais formais.

As atividades lúdicas na EJA/Campo em uma escola pública da comunidade quilombola de Feira de Santana, foco deste estudo, aponta para o desafio de trabalhar mais com a realidade vivenciada pelos alunos, diariamente, em seu cotidiano. É necessário considerar, ainda, os aspectos culturais e sociais que envolvem seus costumes e crenças, de modo a valorizar essas manifestações e inseri-las em sala de aula como conteúdos pedagógicos. A ludicidade nesse contexto é praticada quando os alunos passam a reconhecer e experimentar os conhecimentos provindos de sua realidade como conteúdos educativos, compartilhando saberes e obtendo maior potencial crítico e reflexivo, tornando-se sujeitos ativos de seu próprio aprendizado.

Evidenciou-se que os alunos são tímidos e, por esta razão, são praticadas poucas atividades lúdicas em sala de aula. Além disso, a escola não apresenta materiais didáticos adequados e muitos alunos preferem aulas tradicionais e expositivas. Com isso, sugere-se a realização de debates, seminários e rodas de conversas sobre as experiências vividas pelos alunos em sua rotina de trabalho, a fim de compartilhar informações e possibilitar o alcance de maior conhecimento a partir da coletividade e trabalho em grupo. Outras atividades aliadas ao entretenimento e lazer também podem ser desenvolvidas, a fim de ampliar o caráter lúdico e tornar o aprendizado 
mais dinâmico e prazeroso. Porém é de fundamental importância que a escola não busque a prática de ações simplistas que trazem apenas diversão, mas sim o conhecimento com a vivência, que contribuirá para a formação do potencial crítico e reflexivo dos discentes.

Com isso, para viabilizar a aprendizagem na EJA/Campo, propõe-se a adoção da Pedagogia da Alternância com atividades lúdicas, onde as propostas educativas se dividem em tempo-escola e tempo-comunidade, incentivando a integração entre a realidade e vivências em comunidade dos alunos com os conteúdos curriculares, associando teoria e prática. Esta pedagogia, quando apoiada pelo caráter da ludicidade, é capaz de ampliar, de maneira significativa, o potencial de aprendizado dos alunos, pois incentiva um saber criativo, dinâmico e mais prazeroso, especialmente para os alunos dessa modalidade educativa que enfrentam diversas dificuldades para frequentarem as salas de aula.

\section{Sugere-se,}

portanto, O desenvolvimento de uma experiência piloto para se trabalhar na EJA/Campo com a Pedagogia da Alternância, de modo a flexibilizar os horários e conjugar os conteúdos escolares com as atividades desenvolvidas nas unidades produtivas dos estudantes, para contribuir com a permanência dos estudantes na EJA, valorizando-os enquanto sujeitos ativos no processo de aprendizagem e nos seus espaços de trabalho. Assim, a Pedagogia da Alternância pode possibilitar a mediação de práticas educativas que busquem incentivar a permanência dos estudantes na escola e fomentar a obtenção de conhecimentos significativos, perspectivando a transformação das condições de produção da vida dos sujeitos que vivem e trabalham no campo.

\section{Referências}

Ajala, M. C. (2011). Aluno EJA: motivos de abandono e retorno escolar na modalidade EJA e expectativas pós EJA em Santa Helena-PR. Medianeira-PR: Leitura.

Alencar, F. S., Santos, S. M., \& Carvalho, W. L. (2016). Educação de Jovens e Adultos e Educação do Campo: um diálogo para o fortalecimento de direitos do trabalhador/a campesino/a. Recuperado de: http://www.coloquio.paulofreire.org.br.

Almeida, C. M. M. (2016). O uso do lúdico no ensino de ciências: jogo didático sobre a química atmosférica. Revista Góndola: Enseñanza y Aprendizaje de las Ciências, 11(2), 25-36. https://doi.org/10.14483/udistrital.jour.gdla .2016.v11n2.a5

Apaz, M. F. (2012). A relação entre o aprender $e$ o brincar: uma perspectiva psicopedagógica. Recuperado de: http://www.abpp.com.br/artigos/131.pdf.

Araújo, A. S., \& Porto, K. S. (2019). Vivências de estágio supervisionado em 
Ciências da Natureza em uma escola do campo: reflexão das práticas pedagógicas na formação inicial de professores da Educação do Campo. Revista Brasileira De Educação Do Campo, 4, e4132. https://doi.org/10.20873/uft.rbec.v4e4132

Arroyo, M., Caldart, R. S., \& Molina, M. C. (2011). Por uma Educação do Campo. Rio de Janeiro: Vozes.

Arroyo, M. (2017). Passageiros da noite: do trabalho para a EJA, itinerários pelo direito a uma vida justa. Petrópolis: Vozes.

Borghi, I. S. M., \& Porto, K. S. (2019). A importância dos saberes acadêmicos e dos saberes populares na formação de educadores da educação do campo. Acta Scientiarum. Education, 41(1), e40063. https://doi.org/10.4025/actascieduc.v41i1.4 0063

Castilho, M. A., \& Tonus, L. O. (2008). O lúdico e sua importância na formação de jovens e adultos. Synergismus Scyentyfica Revista da UTFPR, 3(23), 1-4.

Ferreira, P. N. P., \& Porto, K. S. (2020). Práticas Pedagógicas desenvolvidas com alunos com deficiência: um estudo de caso em uma escola do campo de Feira de Santana - BA. Revista Brasileira De Educação Do Campo, 5, e7913. https://doi.org/10.20873/uft.rbec.e7913

Freire, P. (1967). Educação como prática da liberdade. Rio de Janeiro: Paz e Terra.

Galdino, A., Galdino, S., \& Bastos, M. F. S. A. (2012). A ludicidade como mediação pedagógica no contexto da educação de jovens e adultos na Escola Municipal Marcionílio Rosa - Irecê/BA. Discentis, 1(2), 14-26.

Gerhardt, T. E., \& Silveira, D. (2009). Métodos de Pesquisa. Porto Alegre: SEAD/UFRGS.
Lakatos, E. M., \& Marconi, M. de A. (2010). Fundamentos de metodologia científica, (5). São Paulo: Atlas.

Leite, N. C., \& Belo, A. L. M. (2016). A importância da ludicidade na educação de Jovens e Adultos: um estudo numa escola pública do município Macapá/AP. Recuperado de: http://www.monografias.com/pt/trabalhos3 importancia-educacao-jovensadultos/.shtml.

Lopes, K. R., Mendes, R. P., \& Faria V. L. B. de (2006). Coleção Proinfantil: módulo IV, Unidade 5. Brasília: MEC. Secretaria de Educação a Distância, 2.

Luckesi, C. (2014). Ludicidade e formação do educador. Revista Entre Ideias, 3(2), 13-23. $\quad$ https://doi.org/10.9771/23171219rf.v3i2.9168

Lüdke, M., \& André, M. E.D.A. (1986). Pesquisa em educação: abordagens qualitativas. São Paulo: EPU.

Moreira, M. A., \& Pinto, A. O. (2003). Dificuldades dos Alunos na Aprendizagem da Lei de Ampère, à Luz da Teoria dos Modelos Mentais de Johnson-Laird. Revista Brasileira de Ensino de Ciências, 25(3), 36-46.

https://doi.org/10.1590/S010247442003000300009

Oliveira, E., Rodrigues, M. S., Souza, R. S., Souza, R. S., \& Guimarães, A. R. (2016). O lúdico na Educação de Jovens e Adultos. Recuperado de: http://alb.org.br/arquivomorto/edicoes_anteriores/anais16/sem01pd f/sm01ss04_08.pdf.

Porto, K. S., Duboc, M. J. O., \& Ribeiro, S. L. (2021). Educação do campo e inclusão de alunos com deficiência: percepções e práticas docentes. Educação Em Foco, 24(42), 110-133. https://doi.org/10.24934/eef.v24i42.4836 
Resolução n. 1, de 3 de abril de 2002, (2002, 3 de abril). Dispõe sobre as Diretrizes operacionais para a educação básica nas escolas do campo. Recuperado de:

http://portal.mec.gov.br/cne/arquivos/pdf/C EB012002.pdf

Santos, J., \& Porto, K. (2020). Vivências de estágio de ciências da natureza no contexto da educação do campo: uma análise crítico-reflexiva. Revista Brasileira De Ensino De Ciências e Matemática, 3(1).

https://doi.org/10.5335/rbecm.v3i1.10238

Santos, C., de Jesus, J., \& Porto, K. (2020). O ensino e a aprendizagem de Matemática na perspectiva da Educação do Campo e da Etnomatemática. Revista de Ensino de Ciências E Matemática,11(6), 937-957. https://doi.org/10.26843/rencima.v11i6.26 $\underline{88}$

Silva, L. H. (2003). As experiências de formação de jovens do campo Alternância ou Alternâncias? Viçosa: Editora UFV.

Silva, L. H., \& Miranda, E. L. (2012). Formação por alternância na Educação de Jovens e Adultos no campo. Recuperado de:

file:///D:/Downloads/_arquivos_29530de2 $\underline{1430}$

Silva. M. S. (2009). As práticas pedagógicas das escolas do campo: a escola na vida e a vida como escola. (Tese de Doutorado). Universidade Federal de Pernambuco, Recife.

Vasconcellos, C. S. (2000). Planejamento Projeto de Ensino-Aprendizagem e Projeto Político-Pedagógico. 7. ed. São Paulo: Ladermos Libertad-1.

Vygotsky, L. S. (1989). A formação social da mente. São Paulo: Martins Fontes. i Entende-se por populações do campo os agricultores familiares, os extrativistas, os pescadores artesanais, os ribeirinhos, os assentados e acampados da reforma agrária, os trabalhadores assalariados rurais, os quilombolas, os caiçaras, os povos da floresta, os caboclos e outros que produzam suas condições materiais de existência a partir do trabalho no meio rural (Brasil, 2010).

Informações do Artigo / Article Information

Recebido em : 17/06/2020

Aprovado em: 13/03/2021

Publicado em: 30/11/2021

Received on June 17th, 2020

Accepted on March 13th, 2021

Published on November, 30th, 2021

Contribuições no Artigo: Os(as) autores(as) foram os(as) responsáveis por todas as etapas e resultados da pesquisa, a saber: elaboração, análise e interpretação dos dados; escrita e revisão do conteúdo do manuscrito e; aprovação da versão final publicada.

Author Contributions: The author were responsible for the designing, delineating, analyzing and interpreting the data, production of the manuscript, critical revision of the content and approval of the final version published.

Conflitos de Interesse: Os(as) autores(as) declararam não haver nenhum conflito de interesse referente a este artigo.

Conflict of Interest: None reported.

Avaliação do artigo

Artigo avaliado por pares.

\section{Article Peer Review}

Double review.

Agência de Fomento

Não tem.

Funding 
No funding.

Como citar este artigo / How to cite this article

APA

Souza, S. V., Borghi, I. S. M., Mendes, M. P. L. Porto, K. S. (2021). A ludicidade na EJA/Campo no contexto de uma escola da Comunidade de Matinha dos Pretos, Feira de Santana - BA. Rev. Bras. Educ. Camp., 6, e9057. http://dx.doi.org/10.20873/uft.rbec.e9057

\section{ABNT}

SOUZA, S. V.; BORGHI, I. S. M.; MENDES, M. P. L.; PORTO, K. S. A ludicidade na EJA/Campo no contexto de uma escola da Comunidade de Matinha dos Pretos, Feira de Santana - BA. Rev. Bras. Educ. Camp., Tocantinópolis, v. 6, e9057, 2021. http://dx.doi.org/10.20873/uft.rbec.e9057 